remember rightly, gastroscopy has been reported as confirming this supposition.

In view of the utter uselessness of all treatment up till now any therapeutic measure would be welcome. The peculiar sensitivity of the skin would suggest a trial of "benadryl." This might be a valuable measure in those cases with eye lesions where any decrease of inflammation would mitigate the cumulative and recurrent damage to these organs.-I am, etc.,

$$
\text { Oxford. }
$$$$
\text { G. WhitWELl. }
$$

\section{Endocrine Receptors}

Sir,-Mr. Aleck Bourne's admirable survey of the endocrines in gynaecology (Jan. 18, p. 79) deserves high praise, and he is right in drawing attention to that neglected aspect of hormonal physiology, the reacting tissues, though whether the hypothesis of the "endocrine receptor" is necessary or not is another matter. That the question has not escaped the attention of all endocrinologists may be illustrated, for example, by the emphasis which $\mathrm{H}$. Zondek (The Diseases of the Endocrine Glands, London, 1944) has placed on the importance of variability in the responsiveness of reacting tissues in bringing about some of the results observed in certain endocrinopathies. Cases such as that of Mr. Aleck Bourne in which vaginal but not uterine responsiveness to oestrogens occurred are not so rare nor so exclusive as may be imagined; Zondek, for instance, describes a number of cases of undoubted Graves's disease which were accompanied by obesity, either generalized or localized, while the instances of localized gigantism and the very common occurrence of wide variations in the degree of development of different secondary sexual characters in individuals (males, perhaps, more than females) may also be cited as examples of localized hyper-reactivity or unresponsiveness of certain tissues to various hormones.

The variation in responsiveness of certain tissues to hormonal influences is, indeed, a matter of everyday occurrence in the case of the alteration of sensitivity of the uterus during pregnancy to the oxytocic fraction of the posterior pituitary, and it is difficult to see here how the postulation of a receptor substance, or its presence in altered amount, can help to explain the observed phenomena. By all means, then, let due and increasing attention be paid to the question of the responsiveness of tissues to hormonal action, but let us at the same time avoid, as far as possible, complicating the already complex by the postulation of nebulous substances whose existence may well be impossible to prove.-I am, etc.,

London, N.W.3.

G. I. M. SWYER.

\section{Endogenons Depression in General Practice}

SiR,-The letter (Jan. 18, p. 111) by Dr. A. Lionel Rowson should not, I think, pass without comment. Has he ever worked in a mental hospital? If so, it is difficult to understand the language of his first two paragraphs, which is both diffuse and, I submit, inaccurate-certainly not helpful.

Dr. Rowson does not take count of the constructive side of the problem. Patients are as a rule sent to mental hospitals because their relatives and/or their doctor have not the necessary facilities for adequate treatment. Nowadays the average mental hospital is staffed by intelligent medical officers who are keen on the curative side of their work, and in addition run clinics for out-patients to which the general practitioner brings or sends his patient for consultation. Moreover, in the hospital itself much use is now being made of many modern methods of treatment. I would mention electro-convulsion therapy as an example. It is not quite clear what Dr. Rowson means by endogenous depression-i.e., whether manic-depressive psychosis or anxiety neurosis. E.C.T. cures a large number of the former, and the consultative clinic of the latter. But they are quite different conditions.

Everyone who has worked in the larger mental hospitals would welcome improvements such as smaller wards and more female staff for the chronic cases, but those patients with acute depression are nowadays customarily treated in the "admission" or "acute" wards, which are well equipped both for diagnosis and therapy. For those who can afford a moderate inclusive charge a private institution is often very suitable for cases of anxiety neurosis. I have myself worked in both types. Additional facilities for the cure of depressed cases are to be found in occupation therapy and the services of a good hospital chaplain.-I am, etc.,

\section{Cambridge.}

\section{A. KNyVETt GoRdon.}

\section{Protein Requirements of Adults}

SIR, - With reference to the leading article on the above subject (Jan. 4, p. 19) I should like to point out that all protein requirement values based on balances are quite unreliable. Everything being equal, the "requirement" varies in inverse ratio to the length of the period during which the subject has become used to a low protein intake. With a protein intake which even for three months may give a negative balance, if the experiment is continued long enough, an equilibrium is frequently obtained. It is quite impossible to say what the minimum protein requirement is. Moreover, it varies considerably from individual to individual, depending as it does on the function of the thyroid, etc. (High Blood Pressure, 1937).

In the treatment of high blood pressure we found it was desirable to obtain requirement values for each individual. But it is not generally realized that the availability of other substances, such as a large intake of inorganic bases, influences protein requirement (Harris, I., Ireland, J. T., and James, G. V., J. Physiol., 1941, 99, 370). Apparently the substances which are available in large quantities are more readily utilized. This has the force of a physiological law (Harris, I. et al., Studies in Hypertony and Prevention of Disease, 1946). Requirement value of protein not only depends on the protein intake but on the availability of other substances. Balances are clearly no evidence at all of requirement. The minimum protein requirement is unknown, and it is difficult to discover what the optimum protein requirement is. It is equally possible to obtain an equilibrium on a 25 -grammes-of-nitrogen intake and on a 5-grammes intake per day. The question arises, Which represents the optimum requirement? We do not know. The only way to find out the optimum requirement of protein and of many other substances is by prolonged clinical observation. A number of high blood pressure cases on low protein have been under my observation for some time, and at the Institute of Research for the Prevention of Disease a number of normal cases are kept on low protein diet, and from time to time their intake of nitrogen is checked by the determination of urinary nitrogen. Only in this way will it be ultimately possible to find out which is the optimum protein requirement. It would be very valuable if all workers interested in the subject would co-operate in this most valuable experiment, pooling resources; for it is necessary to have a very large number of cases under observation for a very long period before a definite conclusion can be arrived at.-I am, etc.,

Liverpool.

I. HARRIS.

\section{Secondary Abdominal Pregnancy}

SIR, - An account of a case of this rare condition may be of interest.

\section{CASE RePORT}

The patient was a Bantu woman aged about 25 or 30 . She stated that her husband had had syphilis, untreated except by native medicine, and that of her three children the first was stillborn, the second died at the age of 5 months, and the third died at 2 years. The causes of death were urknown-presumably syphilis.

She was admitted here at full term on June 15, 1946, and antisyphilitic treatment was begun. The abdomen was the size of a nine-months pregnancy and the child lying as a breech presentation. No abnormality was suspected at this time. On June 25 ol. ricin and an enema were given to try to induce labour, and this was repeated the next day and on July 4 . On June 30 the child was found to be Tying transversely; it was turned to a breech presentation and a binder applied. On July 2 the presentation was difficult to define; the limbs were felt near the umbilicus. For the next three days the woman had intermittently what appeared to be labour pains, but on vaginal examination there was no "show" and no dilatation of the cervix, which was noted to be firmer than usual for full-term pregnancy. The presenting part icould not be clearly felt. On July 5 the "labour pains" began again, and the patient's general condition began to deteriorate. To our surprise she not only consented to operation but asked for it. The women here are often reluctant to undergo operation. 